Article

\title{
Overview of Low-Level Wind Shear Characteristics over Chinese Mainland
}

\author{
Caiyan Lin ${ }^{1}$, Kaijun Zhang ${ }^{2}$, Xintao Chen ${ }^{1}$, Sheng Liang ${ }^{1}$, Junjie $\mathrm{Wu}^{3}$ and Wei Zhang ${ }^{1,4, *}$ \\ 1 Aviation Meteorological Center, Air Traffic Management Bureau, Civil Aviation Administration of China, \\ Beijing 100122, China; lincaiyan@atmb.net.cn (C.L.); 1501210129@pku.edu.cn (X.C.); \\ liangsheng@atmb.net.cn (S.L.) \\ 2 Gansu Sub-Bureau of Northwest Air Traffic Management Bureau, Civil Aviation Administration of China, \\ Lanzhou 730087, China; kkjjzh@163.com \\ 3 College of Air Traffic Management, Civil Aviation Flight University of China, Guanghan 618300, China; \\ wjunj@mail3.sysu.edu.cn \\ 4 College of Civil Aviation, Nanjing University of Aeronautics and Astronautics, Nanjing 211106, China \\ * Correspondence: frogwei@atmb.net.cn
}

Citation: Lin, C.; Zhang, K.; Chen, X.; Liang, S.; Wu, J.; Zhang, W. Overview of Low-Level Wind Shear

Characteristics over Chinese Mainland. Atmosphere 2021, 12, 628. https://doi.org/10.3390/atmos 12050628

Academic Editors: Douglas Boyd and Thomas Guinn

Received: 3 April 2021

Accepted: 11 May 2021

Published: 14 May 2021

Publisher's Note: MDPI stays neutral with regard to jurisdictional claims in published maps and institutional affiliations.

Copyright: (c) 2021 by the authors. Licensee MDPI, Basel, Switzerland. This article is an open access article distributed under the terms and conditions of the Creative Commons Attribution (CC BY) license (https:// creativecommons.org/licenses/by/ $4.0 /)$.

\begin{abstract}
The characteristics of low-level wind shear (LLWS) over the Chinese mainland were investigated using reports from pilots, air traffic controllers and the number of arriving/departing flights from 2016 to 2020. A preliminary analysis of the impact of the flights on the LLWS reports was carried out, and the cause of LLWS was also investigated. LLWS reports from most airports indicate that LLWS is most likely to occur within $600 \mathrm{~m}$ AGL with a higher density below $300 \mathrm{~m}$, but with some exceptions, as wind shear is reported at higher altitudes at some airports. Airports with a high frequency of LLWS reports are almost all located in or around regions with complex topography and in regions with prevailing weather conditions favorable to LLWS. The variation in overall LLWS reports displays a steady increase from 2016 to 2019 and a decrease from 2019 to 2020, consistent with the trend in the number of flights, but with no evidently similar trends for individual airports. Seasonal variations in LLWS reports are observed and demonstrate no notable impact caused by the number of flights, implying that the main cause is the monthly variation of weather conditions. Diurnal variation is also evident and largely associated with the variation in number of flights during the busy period in addition to weather conditions, such as common strong winds, in the afternoon.
\end{abstract}

Keywords: low-level wind shear; hazardous weather; weather impact on aviation

\section{Introduction}

Wind shear refers to a sudden, drastic change in wind speed or wind direction in the atmosphere, while low-level wind shear (LLWS) is defined as wind shear occurring within $600 \mathrm{~m}$ above ground level. LLWS is commonly associated with thunderstorms, frontal systems, low-level jet streams and low-level temperature inversions, and specifically related to the unique wind-shear conditions resulting from the distribution of buildings, natural obstructions, terrain roughness and land/water interfaces, etc., at and around a particular airport [1].

LLWS is regarded as the most hazardous meteorological phenomenon to an aircraft by subjecting the aircraft to violent updrafts and downdrafts as well as sudden changes to the horizontal movement of the aircraft, and even causing disastrous accidents during the takeoff and landing phases. According to the annual safety reports by the International Civil Aviation Organization (ICAO) [2-6], there were 102 aircraft accidents caused by turbulence, wind shear or thunderstorms, which account for nearly $22 \%$ of the total 467 accidents from 2015 to 2019 and caused 107 fatalities. The reports from 2017 to 2019 note that there were 11 aircraft accidents in which wind shear was explicitly cited as a contributory factor, which caused 41 fatalities. With the rapid growth in flights, it is becoming more and more urgent 
to improve the ability of detecting, diagnosing, alerting, warning or even forecasting LLWS in advance to ensure the safety, regularity and efficiency of flight operations.

Significant advances have been made in the detection and alerts of LLWS, which have made great contributions to the decrease in aircraft accidents caused by LLWS. Standard meteorological instruments such as remote-sensing anemometers on existing television masts and towers were installed in some states to measure wind shear, while specific equipment designed to detect and alert LLWS has also been developed since 1987, including both ground-based and airborne equipment, such as the Doppler radar, Doppler light detection and ranging (lidar) and wind lidars [7]. A low-level wind shear alerting system (LLWAS) based on anemometers was developed to detect wind shear first in 1970s and widely used and improved in the United States since 1970s [8]. A LLWAS was also developed by Hong Kong Observatory (HKO) and has been utilized in the Hong Kong International Airport (HKIA) since the 1970s, and has continuously improved based on the wind data collected by the surface-based anemometers, infrared Doppler lidar, the spectral width data of the terminal Doppler weather radar, short-range lidar, ground-based and multi-channel microwave radiometer, etc. [9-13].

In the Chinese mainland, there are also some efforts being made to enhance the detection and alerts of LLWS, especially regarding the installation of some advanced equipment at airports vulnerable to LLWS; however, no LLWAS has been developed to date. For example, Beijing Capital International Airport (ICAO location indicator: ZBAA; hereinafter, airports are all abbreviated by ICAO location indicators) applied a pulse coherent Doppler lidar system, which can capture the small-scale characteristics of wind and turbulence to detect LLWS $[14,15]$. A coherent Doppler lidar was also installed in Lanzhou Zhongchuan International Airport (ZLLL) for experimental application in 2016, and a corresponding algorithm was developed to alert LLWS [16]. In Kunming Changshui International Airport (ZPPP), a dual polarization Doppler radar, a wind profiler and a wind lidar were installed to enhance the detection and alert of LLWS [17].

Furthermore, progress on the diagnosis and analysis of LLWS has also been made in the past two decades for many airports to help understand the characteristics of LLWS and its triggering mechanisms. In Chinese mainland, there have also been many studies on the diagnosis or analysis of the characteristics and the cause of LLWS in particular airports. For example, the diagnostic analysis of LLWS cases at ZBAA during 2007-2008 shows that LLWS has the greatest occurrence in spring, followed by winter, with the least occurrence in summer [18]. The study on the characteristics of LLWS at ZBAA during 2010-2014 denotes that the greatest number of LLWS reports occurred in winter followed by spring with the least in autumn [19]. The investigation regarding the LLWS during 20112018 in Dalian Zhoushuizi International Airport (ZYTL) indicates that the most frequent LLWS occurred in spring followed by autumn with the least occurrence in winter [20]. The case study at ZLLL during 2004-2007 shows that LLWS happened frequently from March to December, especially in May and June, and was mainly related to convective activities [21]. The characteristics of LLWS in Xining Caojiapu International Airport (ZLXN) during 2011-2014 were investigated, with the greatest occurrence in spring, followed by summer, with the highest frequency in early evening during the day [22]. The analysis of the LLWS cases at airports in Southwest China from March 2008 to September 2011 shows the LLWS mainly occurred in spring and summer and was largely associated with thermal low pressure, low-level jet stream, troughs, a quasi-stationary front and a gust front triggered by thunderstorms [23]. These kinds of studies were generally conducted on a particular airport, which are largely based on the limited Pilot Reports (PIREPs).

In addition, there are also several studies trying to simulate and predict LLWS using numerical prediction models as well as investigating the impact of the lidar data on LLWS numerical simulations $[18,24,25]$; however, encouraging results have not been achieved, and it is not currently applicable in routine operations.

Overall, due to the small-scale and short-lived characteristics of LLWS and its uniqueness at particular airports, and despite of all the progress made concerning the LLWS, it 
is still rather difficult to detect, alert, warn and even forecast the occurrence of LLWS in advance. Due to the cost expense and maintenance of the specific equipment designed for wind shear detection and the limited knowledge of the characteristics and the triggering mechanism of LLWS, it is still in the feasibility study of the installation of equipment in the majority of airports across Chinese mainland. The development of LLWAS and its efficacy are also under evaluation.

With the increase in observations associated with the increase in flight operations and new transmitting means, as well as other observations based on new advanced instruments and the change of weather conditions due to climate change, it is necessary to conduct a comprehensive study on the spatial-temporal characteristics of LLWS over Chinese mainland and update the results with these new observations. This will be very helpful to better understand the characteristics and the mechanisms of LLWS in Chinese mainland. Therefore, this study is mainly focused on analyzing the spatial-temporal characteristics of LLWS in Chinese mainland to give more knowledge and provide a reference for the practice of better detection, alerting, warning and even forecasting of LLWS in the future.

The paper is arranged as follows. An overview of the data and method used in this study is given in Section 2. Section 3 describes the results. The discussion and conclusions are finally presented in Section 4.

\section{Data and Method}

Air Traffic Controller Reports for aviation abnormal events (hereinafter referred to as ATCREPs) and Pilot Reports (PIREPs) associated with wind shear collected from 2016 to 2020 are used to analyze the characteristics of wind shear occurring at or close to the airports in Chinese mainland, among which reports of some new airports operated after 2016 are collected from their operations.

A report of aviation abnormal event is recorded by air traffic controllers at a related airport and generally transmitted after the event, describing abnormal situations such as aborted approach, go-around, diversion or rejected take-off due to weather, aircraft, flight crews, air traffic flow control, passengers, etc. ATCREPs are only reported from the 45 primary airports in Chinese mainland.

A PIREP is reported by a pilot and concerns the actual hazardous weather conditions encountered in flight, such as wind shear, turbulence, ice and thunderstorms. These reports are traditionally transmitted in real time by radio to an appropriate ground station for dissemination, serving as warnings to other pilots, providing air traffic controllers with knowledge of potential weather hazards in order to keep pilots clear of the hazards and helping weather forecasters to update and improve the accuracy of the weather forecasts. PIREPs are collected from all possible civil airports in Chinese mainland.

Since there are some reports of same situations reported in both the ATCREPs and the PIREPs, the two kinds of reports are compared one by one and duplicate reports are removed. The query normal height $(\mathrm{QNH})$ used in some reports for where the wind shear encountered are all converted to the true height above ground level (AGL). In addition, reports of wind shear encountered above $2000 \mathrm{~m}$ AGL are not considered in this study, and those encountered within $600 \mathrm{~m}$ AGL are recognized as reports relating to low-level wind shear (LLWS). After quality control, the remaining reports with about 3200 ATCREPs and 2000 PIREPs relating to wind shear within 2000 m AGL during 2016 to 2020 are used for statistical analysis of the spatial-temporal characteristics of LLWS over Chinese mainland.

In addition, the monthly number of arriving and departing flights handled in Chinese mainland from 2016 to 2020 is also used to compare and demonstrate the extent to which flights are affected by wind shear and the impact of the number of flights on the number of LLWS reports. 


\section{Results}

\subsection{Overall Impacts of Wind Shear}

The ATCREPs regarding abnormal situations with aborted approaches, go-arounds, rejected take-offs or returns can be associated with a variety of factors, such as weather, aircraft, flight crews, air traffic flow control, bird strikes, military-related factors and passengers. According to the statistics of ATCREPs from 2016 to 2020, nearly $32.1 \%$ of events were due to the wind shear, and about $30.7 \%$ were due to low-level wind shear, which is dangerous for flights. Compared to other factors, the impact of wind shear occupies a large proportion, which indicates that the wind shear has an important impact on the flight operation, not only for the regularity and efficiency of flights but also for the safety.

For PIREPs related to the wind shear, nearly $38.1 \%$ reports give an explicit description of the impacts on the flights resulting in aborted approaches and/or go-arounds, while others reported the impact of rejected take-offs, no impact on normal operation or did not indicate the impacts on the flights. It should be noted that even the reports without any information concerning the impacts on the flight may include some events resulting in aborted approaches and/or go-arounds of the flights.

In total, in accordance with the ATCREPs and PIREPs, nearly $76 \%$ of the wind shear reports reported the impact of aborted approaches and/or go-arounds, indicating that most of the wind shear events reported were severe wind shear and seriously affected the flight operations.

\subsection{Spatial Characteristics}

\subsubsection{Horizontal Distribution}

Figure 1 presents the number of LLWS events reported in ATCREPs and PIREPs from 2016 to 2020 at or close to airports in Chinese mainland. There are 115 civil airports (colored dots in the map) with at least one report of LLWS event at each airport in the past five years. Larger symbols indicate more LLWS reports at or close to that airport, which are also denoted by different colors. The results show that the top 20 airports affected by high numbers of LLWS events are those at ZBAA, ZYTL, Hohhot Baita International Airport (ZBHH), ZPPP, ZLLL, Shenyang Taoxian International Airport (ZYTX), Shanghai Pudong International Airport (ZSPD), Xi'an Xianyang International Airport (ZLXY), Shanghai Hongqiao International Airport (ZSSS), Harbin Taiping International Airport (ZYHB), Yinchuan Hedong International Airport (ZLIC), Taiyuan Wusu International Airport (ZBYN), ZLXN, Urumchi Diwopu International Airport (ZWWW), Changchun Longjia International Airport (ZYCC), Qingdao Liuting International Airport (ZSQD), Guangzhou Baiyun International Airport (ZGGG), Lijiang Sanyi International Airport (ZPLJ), Tianjin Binhai International Airport (ZBTJ) and Guiyang Longdongbao International Airport (ZUGY). Out of these 20 airports, 16 are located in the north and west of China, with all primary airports (4) in Northeast China, four primary airports in North China, all primary airports (5) in Northwest China, and three primary airports in Southwest China. The other four primary airports are located in East China (3) and South-Central China (1).

As is well known, the number of LLWS reports at each airport is associated not only with the flight operations performed, but also with the complex topography at and around the airport and the prevailing atmospheric conditions. Complex ground topography and large buildings can break up the flow and create wind gusts with sudden changes in wind direction and speed. Therefore, the main reason for the large amount of LLWS at the majority of these airports is that they are surrounded by complex topography, e.g., they are dominated by mountainous terrain or located in coastal areas and often experience strong winds, which are favorable to wind shear. 


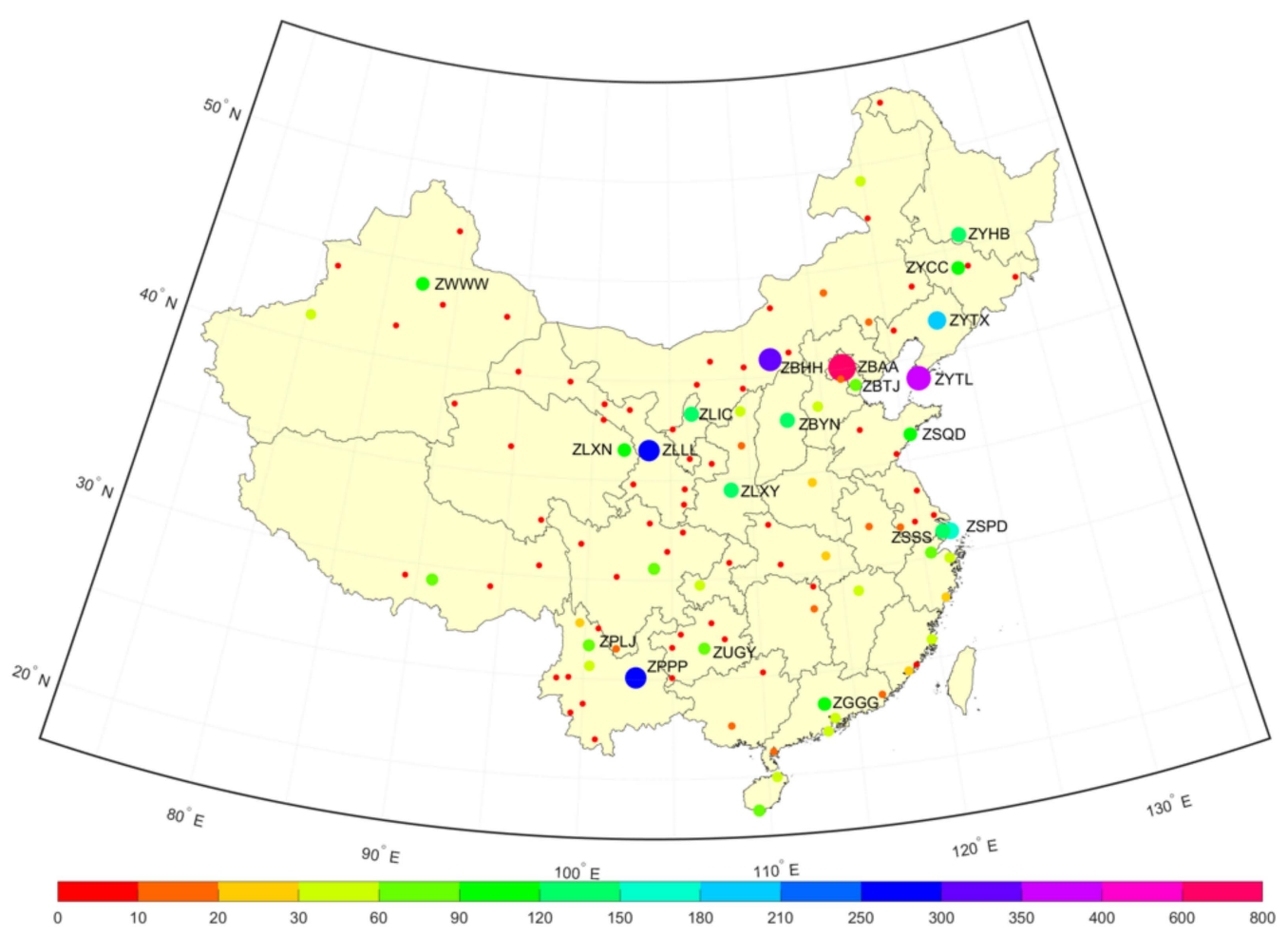

Figure 1. Location of the 115 airports with LLWS reports in Chinese mainland. The size and color of the dots indicate the number of LLWS reports at each airport from 2016 to 2020.

The second reason is that a greater number of arriving/departing flights handled is theoretically one cause for the greater likelihood of LLWS events to be reported. Indeed, most of these 20 airports handle many more flights than other airports with a similar complexity of topography and weather conditions. According to statistics of arriving/departing flights handled by the tower, the top five airports according to flights over Chinese mainland during the past five years are ZBAA (the largest), followed by ZSPD and ZGGG, and then Shenzhen Bao'an International Airport (ZGSZ) and Chengdu Shuangliu International Airport (ZUUU). A total of 15 out of the above top 20 airports according to LLWS reports are ranked in the top 30 airports by the number of flights over Chinese mainland. The number of LLWS reports at ZBAA, the airport with the largest flight volume, is also the largest, almost twice that of ZYTL (the second largest). However, there are some airports at which many more LLWS reports are received, even though they handle less flights than other airports. Additionally, some airports do not receive many LLWS reports even though they handle many more flights, e.g., ZGSZ and ZUUU.

To investigate the extent to which flights are influenced by LLWS at different airports, a comparison was conducted on the LLWS reports and the flights handled by the tower at the above top 20 airports during the period of 2016 and 2020 (Figure 2). The 20 airports of the horizontal axis in Figure 2 are sorted according to the aerodrome elevation (AE), from the lowest to the highest (left to right). An overview of the above 20 airports is also given in Table 1, including the name and acronyms of the airport, their location, rough topography, approximate elevation, the rank according to LLWS reports and the ratio of the number LLWSs to flights. 


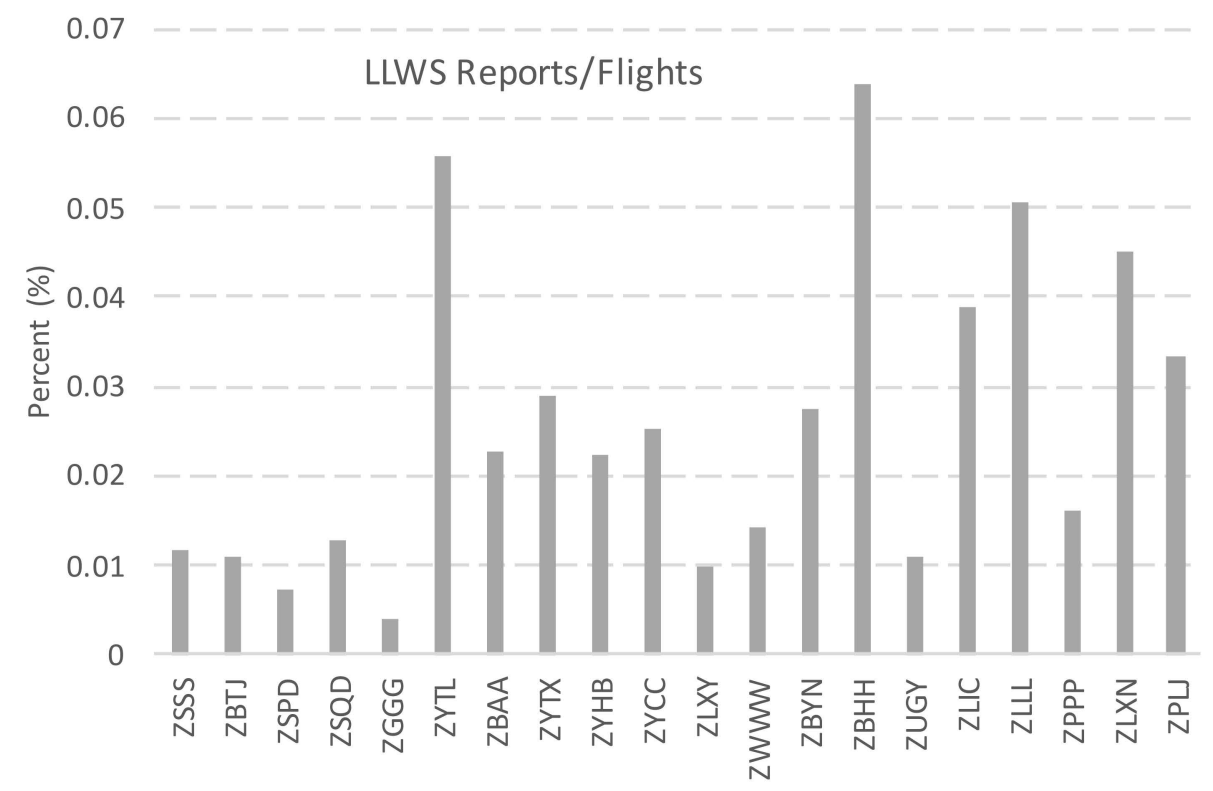

Figure 2. The ratio of number of LLWS reports to flights handled at the 20 airports.

Table 1. Overview of the 20 airports.

\begin{tabular}{|c|c|c|c|c|c|c|}
\hline Airport & $\begin{array}{l}\text { ICAO Location } \\
\text { Indicator }\end{array}$ & Region of China & Topography & Elevation (m) & $\begin{array}{l}\text { Rank According to } \\
\text { LLWS Reports }\end{array}$ & $\begin{array}{c}\text { Rank of Number of } \\
\text { LLWSs/Flights }\end{array}$ \\
\hline $\begin{array}{l}\text { Hohhot Baita International } \\
\text { Airport }\end{array}$ & ZBHH & North China & Mountainous area & 1084 & 3 & 1 \\
\hline $\begin{array}{l}\text { Dalian Zhoushuizi } \\
\text { International Airport }\end{array}$ & ZYTL & Northeast China & $\begin{array}{c}\text { Peninsula, affected } \\
\text { by hills }\end{array}$ & 33 & 2 & 2 \\
\hline $\begin{array}{l}\text { Lanzhou Zhongchuan } \\
\text { International Airport }\end{array}$ & ZLLL & Northwest China & $\begin{array}{l}\text { Plateau area, } \\
\text { surrounded by } \\
\text { mountains }\end{array}$ & 1947 & 5 & 3 \\
\hline $\begin{array}{c}\text { Xining Caojiapu } \\
\text { International Airport }\end{array}$ & ZLXN & Northwest China & $\begin{array}{l}\text { Plateau area, } \\
\text { surrounded by } \\
\text { mountains }\end{array}$ & 2184 & 13 & 4 \\
\hline $\begin{array}{l}\text { Yinchuan Hedong } \\
\text { International Airport }\end{array}$ & ZLIC & Northwest China & $\begin{array}{l}\text { Plateau area, } \\
\text { surrounded by } \\
\text { mountains }\end{array}$ & 1141 & 11 & 5 \\
\hline $\begin{array}{c}\text { Lijiang Sanyi International } \\
\text { Airport }\end{array}$ & ZPLJ & Southwest China & $\begin{array}{l}\text { Plateau area, } \\
\text { surrounded by } \\
\text { mountains }\end{array}$ & 2242 & 18 & 6 \\
\hline $\begin{array}{l}\text { Shenyang Taoxian } \\
\text { International Airport }\end{array}$ & ZYTX & Northeast China & $\begin{array}{l}\text { Northeast plain, } \\
\text { hilly area }\end{array}$ & 60 & 6 & 7 \\
\hline $\begin{array}{c}\text { Taiyuan Wusu International } \\
\text { Airport }\end{array}$ & ZBYN & North China & $\begin{array}{l}\text { Affected by } \\
\text { mountains }\end{array}$ & 786 & 12 & 8 \\
\hline $\begin{array}{l}\text { Changchun Longjia } \\
\text { International Airport }\end{array}$ & ZYCC & Northeast China & $\begin{array}{l}\text { Northeast plain, } \\
\text { hilly area }\end{array}$ & 215 & 15 & 9 \\
\hline $\begin{array}{l}\text { Beijing Capital International } \\
\text { Airport }\end{array}$ & ZBAA & North China & $\begin{array}{l}\text { Mountain-plain } \\
\text { boundary }\end{array}$ & 35 & 1 & 10 \\
\hline $\begin{array}{l}\text { Harbin Taiping International } \\
\text { Airport }\end{array}$ & ZYHB & Northeast China & Northeast plain & 139 & 10 & 11 \\
\hline $\begin{array}{l}\text { Kunming Changshui } \\
\text { International Airport }\end{array}$ & ZPPP & Southwest China & $\begin{array}{l}\text { Plateau area, valley } \\
\text { between mountains }\end{array}$ & 2103 & 4 & 12 \\
\hline $\begin{array}{l}\text { Urumchi Diwopu } \\
\text { International Airport }\end{array}$ & ZWWW & Northwest China & $\begin{array}{l}\text { Valley in Tianshan } \\
\text { Mountain }\end{array}$ & 648 & 14 & 13 \\
\hline $\begin{array}{l}\text { Qingdao Liuting } \\
\text { International Airport }\end{array}$ & ZSQD & East China & Coastal area & 10 & 16 & 14 \\
\hline $\begin{array}{l}\text { Shanghai Hongqiao } \\
\text { International }\end{array}$ & ZSSS & East China & Delta plains & 3 & 9 & 15 \\
\hline $\begin{array}{l}\text { Tianjin Binhai International } \\
\text { Airport }\end{array}$ & ZBTJ & North China & Coastal area & 4 & 19 & 16 \\
\hline $\begin{array}{l}\text { Guiyang Longdongbao } \\
\text { International Airport }\end{array}$ & ZUGY & Southwest China & $\begin{array}{c}\text { Hilly and } \\
\text { mountainous area }\end{array}$ & 1139 & 20 & 17 \\
\hline $\begin{array}{c}\text { X'an Xianyang International } \\
\text { Airport }\end{array}$ & ZLXY & Northwest China & $\begin{array}{l}\text { Guanzhong plain, } \\
\text { affected by } \\
\text { mountains }\end{array}$ & 479 & 8 & 18 \\
\hline $\begin{array}{l}\text { Shanghai Pudong } \\
\text { International Airport }\end{array}$ & ZSPD & East China & Coastal area & 4 & 7 & 19 \\
\hline $\begin{array}{l}\text { Guangzhou Baiyun } \\
\text { International Airport }\end{array}$ & ZGGG & $\begin{array}{l}\text { Middle-South } \\
\text { China }\end{array}$ & $\begin{array}{l}\text { Plain, southern } \\
\text { margin of Nanling } \\
\text { Mountains }\end{array}$ & 15 & 17 & 20 \\
\hline
\end{tabular}


According to the results, compared to the number of flights, there are six airports with more than 3\% of flights reporting LLWS events (ZBHH, followed by ZYTL and ZLLL, and then ZLXN, ZLIC and ZPLJ). These airports are all dominated by complex topography, of which five out of the six airports are located at an altitude higher than $1000 \mathrm{~m}$ in mountainous terrain, with the remaining airport (ZYTL) located in a peninsular and hilly area. The top nine airports with the highest ratios appear in airports ranked outside of the top 20 busiest airports in Chinese mainland according to arriving/departing flights. The results imply that airports in areas with complex topography are much more likely to be affected by LLWS, followed by those with a larger number of flights. It should also be noted that the ratios of LLWS reports to flights are higher in most of the airports with a higher AE.

Moreover, a large number of LLWS reports associated with severe convective weather (thunderstorms), specifically gust fronts and microbursts or tropical cyclones at or near the airports, may not be reported. This is largely because convective weather or tropical cyclones are dangerous to the safety of the flight operation, and air traffic control policies often require that the flights be cancelled or delayed before take-off, be diverted to alternate airports or return while en route or approach to avoid this kind of severe weather. As a result, there are few LLWS reports at or close to airports where LLWS associated with severe convective weather or tropical cyclones would be expected. This demonstrates why some airports much more likely to be affected by thunderstorms show relatively fewer LLWS reports, even with a larger number of flights, especially those airports in East and South-Central China.

\subsubsection{Vertical Distribution}

Figure 3 displays the overall vertical distribution of the total wind shear events encountered which were reported in ATCREPs and PIREPs during the past five years. It shows wind shear events that were likely reported at any height but most likely occurred within $600 \mathrm{~m}$ AGL, with a higher density within $300 \mathrm{~m}$ AGL where wind shear is particularly hazardous due to the proximity of an aircraft to the ground. Samples of the wind shear reports resulting in aborted approaches and/or go-arounds are noted, for which the vertical distribution is displayed in the left part of Figure 3 (separated by a vertical solid line).

The overall cumulative frequency distribution at different heights is shown in Figure 4. The cumulative frequency distribution is a form of a frequency distribution that represents the sum of all events within a given height where wind shear was encountered in this study. It displays that up to $94 \%$ of the wind shear events were encountered within $600 \mathrm{~m}$, namely, low-level wind shear (LLWS), while around 91\% of the events were within $500 \mathrm{~m}$, and more than three-quarters $(77 \%)$ were within $300 \mathrm{~m}$. It is also noted that approximately $5 \%$ of the total wind shear events were encountered at $0 \mathrm{~m}$, namely, on the runway, among which $62 \%$ were explicitly indicated with the impacts leading to touch-and-go landings, which is a critical and risky situation during the landing phase.

A comparison of the cumulative frequency of vertical distribution is performed on the top 20 airports affected by a larger amount of wind shear, shown in Figure 5. It presents the cumulative frequency of the vertical distribution of the heights at $0 \mathrm{~m}$ and within $100 \mathrm{~m}$, $200 \mathrm{~m}, 300 \mathrm{~m}, 400 \mathrm{~m}, 500 \mathrm{~m}$ and $600 \mathrm{~m}$ at the 20 airports. The 20 airports of the horizontal axis are again sorted according to the aerodrome elevation (AE), from the lowest to the highest, as in Figure 2. 


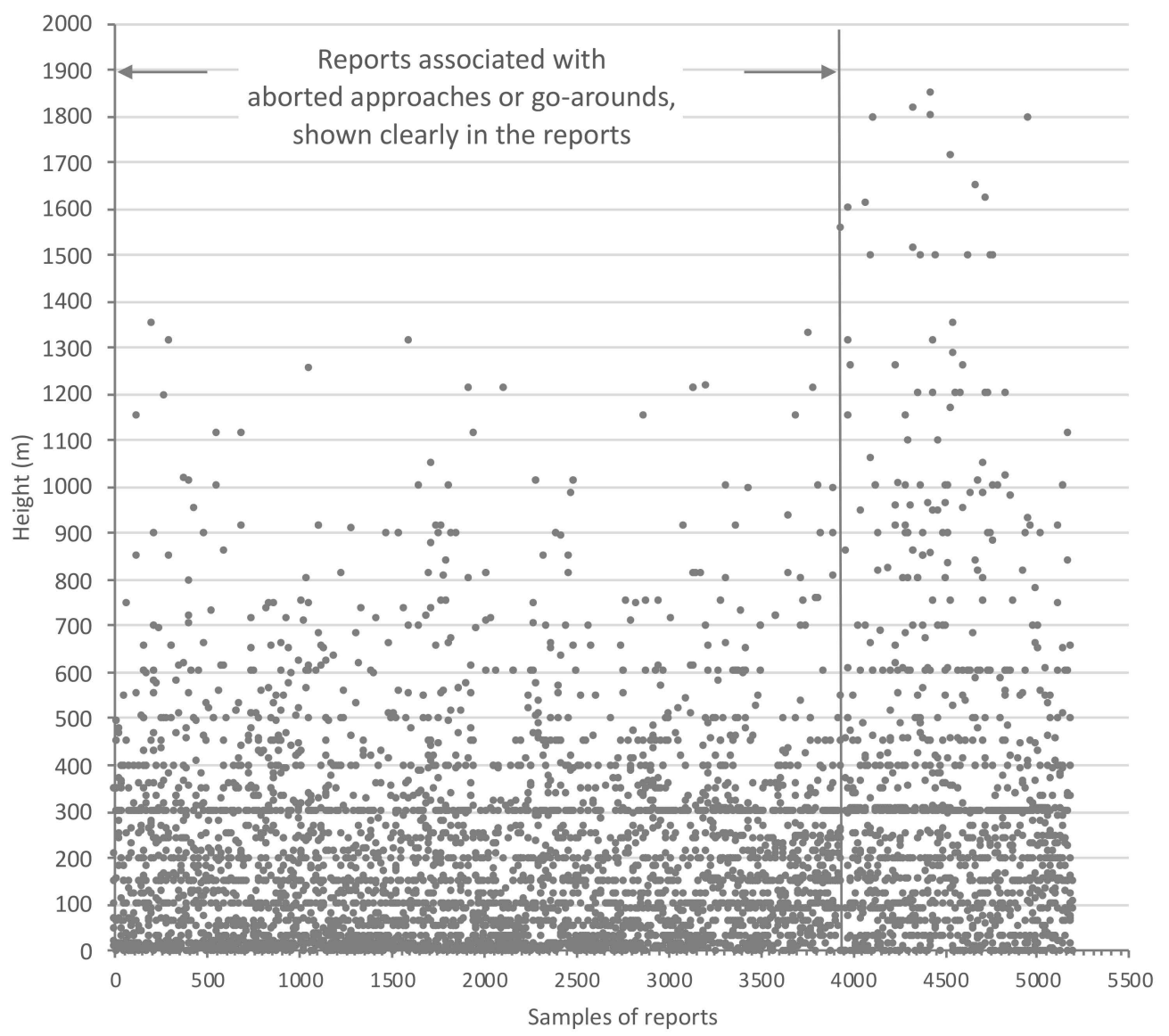

Figure 3. Overall vertical distribution of wind shear reports during 2016-2020 at or close to airports in Chinese mainland.

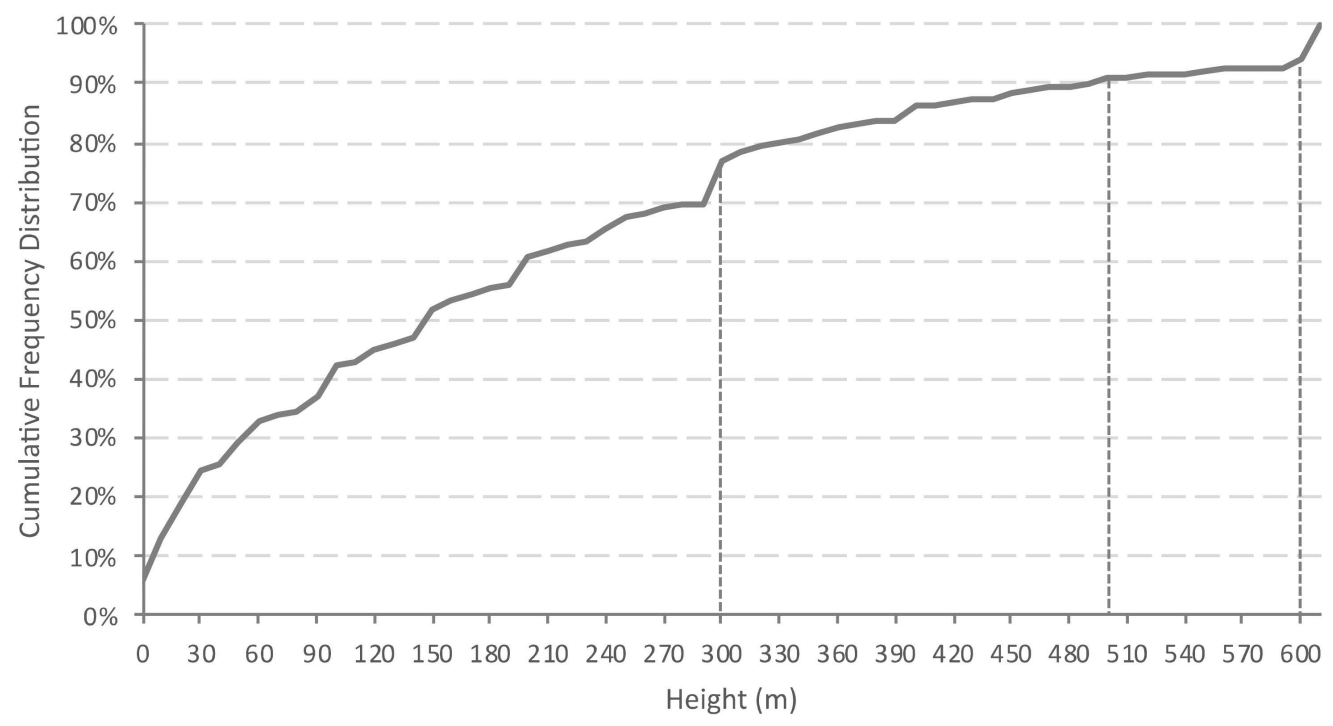

Figure 4. Overall cumulative frequency distribution of LLWS at different heights. 


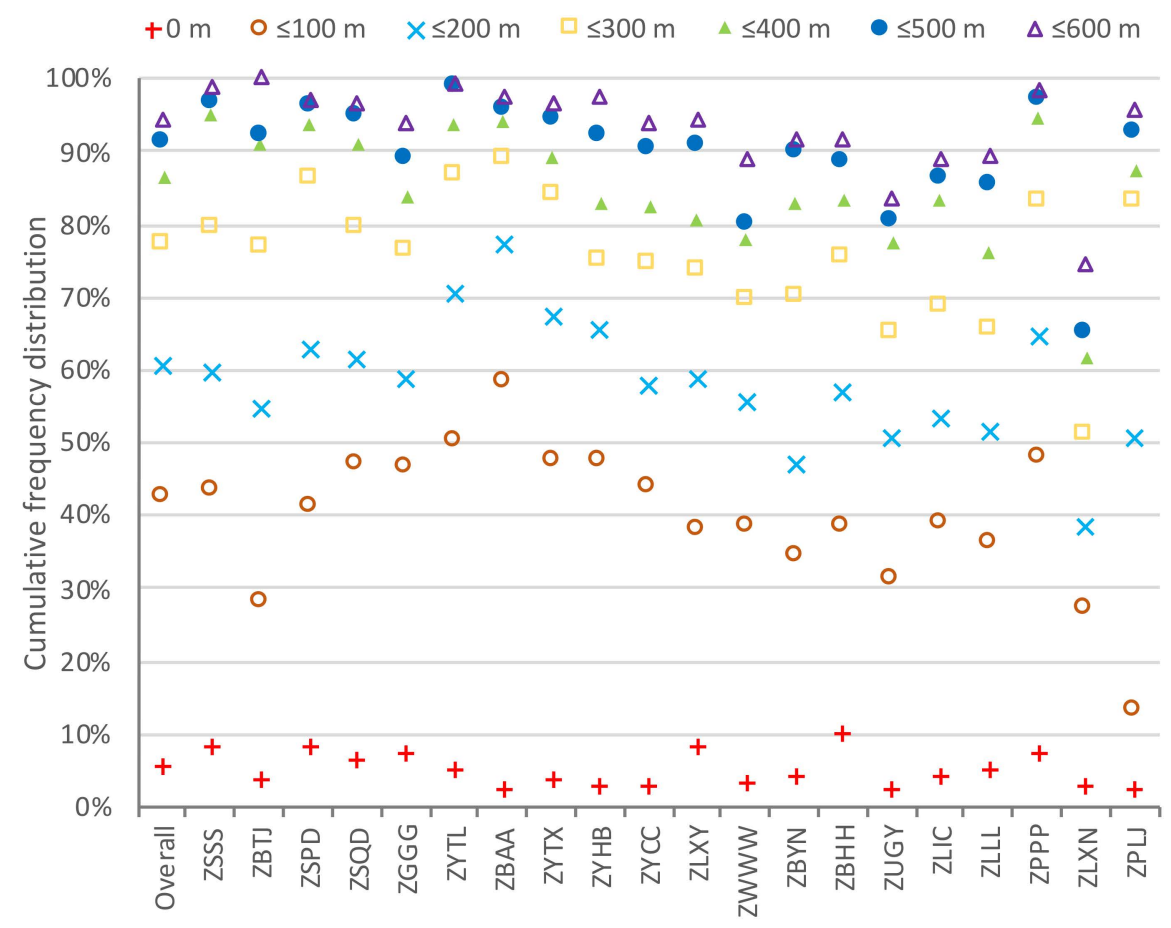

Figure 5. Cumulative frequency distribution of total wind shear events (overall) and that at the 20 airports within different heights.

The results demonstrate that there are some differences in the vertical distribution of the wind shear events at different airports. Firstly, $2-10 \%$ of the reports note that LLWS occurred on the runway, of which $10 \%$ of wind shear events occurred at ZBHH with all attributed to touch-and-go landings that took the aircraft from the short final landing to climb out, touching the runway in the process. Secondly, in general, the wind shear events encountered over airports with lower AE are mainly concentrated within lower heights than those over airports with higher AE, but with some exceptions such as those at ZPPP. For example, around one-half of the LLWS events at ZYTL and more than half (58\%) of the events at ZBAA within $100 \mathrm{~m}$ were reported, and $87 \%$ (99\%) and $89 \%(95 \%)$ within $300 \mathrm{~m}(500 \mathrm{~m})$ were reported at ZYTL and ZBAA, respectively. Only approximately $74 \%$ (the least) of the wind shear events occur within 600m at ZLXN (AE: $2184 \mathrm{~m}$ ), and $84 \%$ (the second to last) of those at ZUGY (AE: $1139 \mathrm{~m}$ ). In addition, at ZLXN, only around $50 \%$ of wind shear events are reported within $300 \mathrm{~m}$, but more than one-quarter $(26 \%)$ of those are above $600 \mathrm{~m}$. However, it is not reasonable to simply conclude that the above results of the vertical distribution are regularly associated with aerodrome elevation, which may be due to many factors that require further investigation, such as the impact of specific surrounding topography along the approach paths.

\subsection{Temporal Characteristics}

\subsubsection{Inter-Annual Variation}

Figure 6 presents the overall variation of the total number of LLWS reports and that of arriving and departing flights in Chinese mainland from 2016 to 2020. As shown in Figure 6, the number of total LLWS reports keeps pace with the number of flights handled in the past five years. The tendency shows that there exists a steady rise in LLWS reports from 2016 to 2019 consistent with an increase in the number of flights. However, following the noticeable decrease in the number of flights due to the worldwide COVID-19 pandemic, the number of LLWS reports also has an obvious reduction. The tendency of the number of LLWS reports and the flights implies that the impact of LLWS is becoming more and more significant with an increase in flight numbers. 


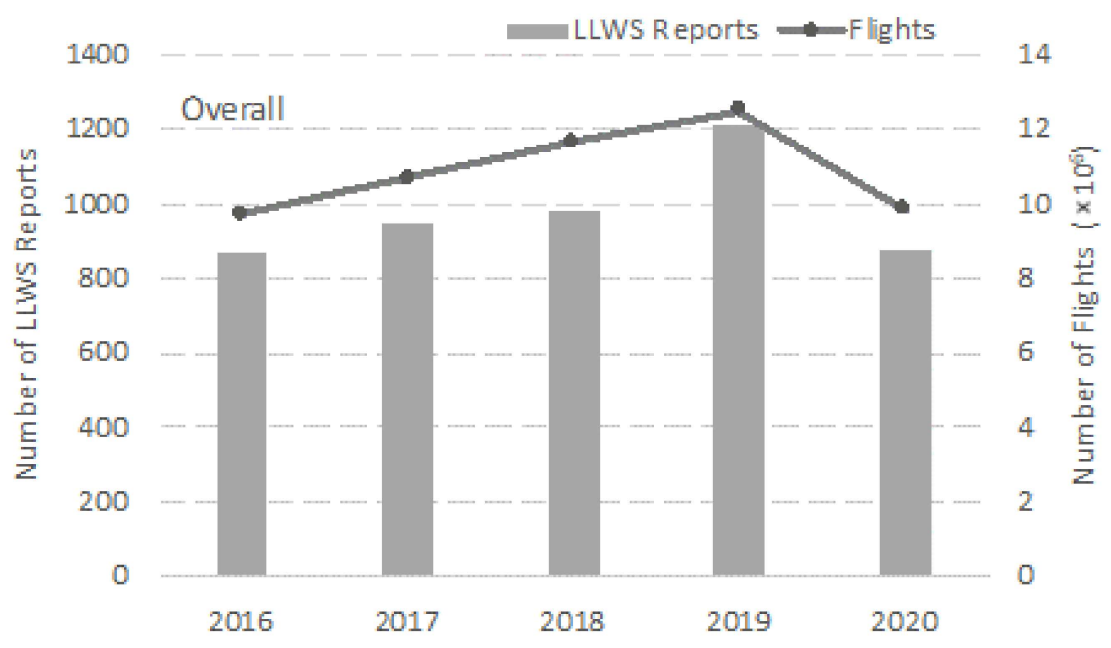

Figure 6. Variation of total LLWS reports and flights in Chinese mainland from 2016 to 2020.

For individual airports, the arriving and departing flights handled almost all show a steady increase from 2016 to 2019 and an obvious decrease in 2020 in all airports, while the inter-annual variation of LLWSs shows a great difference among different airports, with a universal decrease from 2019 to 2020 for most airports, as presented in Figure 7. The results imply that there is no evident increasing or decreasing trend of LLWS reports at most of the airports in the past five years, except that LLWS reports at ZBHH show an obvious increase from 2016 to 2019 and a little decrease in 2020 in addition to a remarkable reduction of the flights. Another exception is that the frequency of LLWS at ZLIC shows no distinct variation from 2016 to 2019 and shows a universal decrease in 2020 as in other airports. In general, both the highest and the lowest frequency of LLWSs at different airports were likely to occur in any year during 2016 to 2019. For example, the statistics of the variation of LLWS in the 20 airports from 2016 to 2020 demonstrate that the highest frequency of LLWS occurred in 2016 at ZLLL, ZPPP and ZSPD; in 2017 at ZBAA, ZBTJ, ZYHB, ZYCC and ZWWW; in 2018 at ZGGG, ZLIC and ZUGY; and in 2019 at ZYTL, ZYTX, ZYCC (same number as in 2017), ZBHH, ZBTY, ZLXY, ZLXN, ZSSS, ZSQD and ZPLJ. However, it should be noted that half of the 20 airports show the highest frequency of LLWS reports in 2019, which is to some extent consistent with the increasing tendency of overall LLWS reports from 2016 to 2019. The reason for no evident tendencies in the LLWS reports over the past five years at each airport is likely related to local climate anomalies, such as more frequent activities of cold air, passes of cold fronts and the corresponding strong winds and wind shear, which happened in some particular years.

\subsubsection{Monthly Variation}

In terms of the monthly variation of the overall LLWS reports and arriving/departing flights (shown in Figure 8), it is evident that the most frequent LLWSs occur in spring (March, April and May), especially in April and May (both with more than 700 LLWS reports), and secondly in summer (June, July and August), which accounts for about $41 \%$ (spring) and 27\% (summer) of the total reports, respectively. A reduced frequency of LLWSs occurs in autumn (September, October and November), with the fewest occurrences in winter (December, January and February), with December having the fewest. By comparison, it is noted that the number of flights does not display an obvious monthly variation, except in February with a marked drop. It indicates that the number of flights is not the main factor contributing to the monthly variation in LLWS reports, which may be largely influenced by the monthly variation in weather conditions. The results denote that the frequency of LLWSs is largely associated with cold frontal systems and strong winds in spring followed by convective weather or convective clouds in summer. There are also much stronger winds in winter; however, due to the combination of strong winds and 
increasing surface temperature in spring, turbulent exchange is much more active than in winter, which contributes to a greater number of LLWS reports in spring.

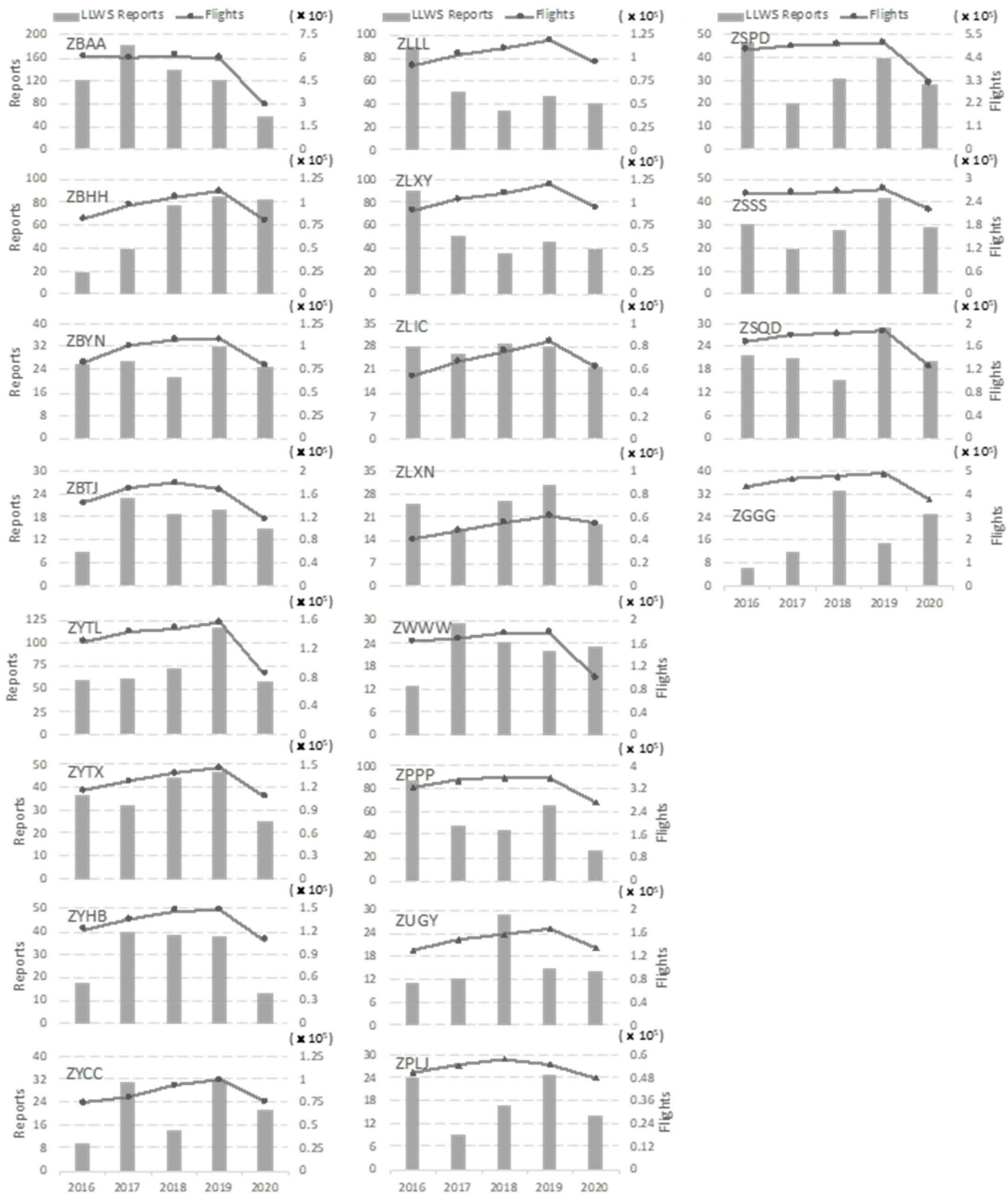

Figure 7. As in Figure 6, but for the 20 airports. 


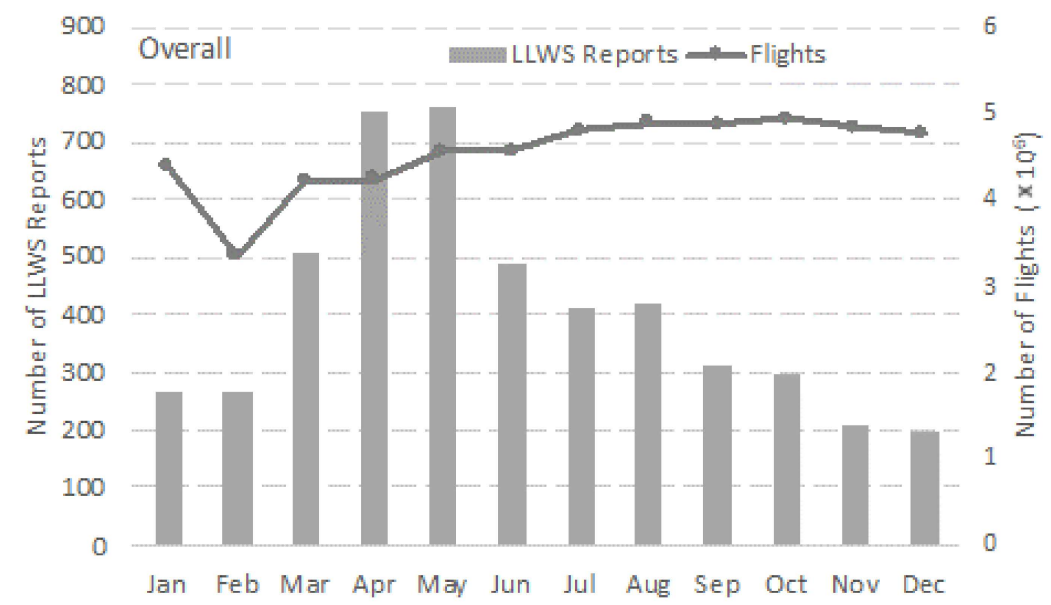

Figure 8. As in Figure 6, but for monthly frequency distribution.

The cumulative monthly frequency and seasonal frequency of the LLWS reports at the 20 airports are displayed in Figures 9 and 10, respectively. The most frequent LLWSs occur in spring at 17 out of the 20 airports (red segment in Figure 10), while at the remaining three airports (ZLLL, ZSSS and ZGGG), the highest frequency of LLWS reports is in summer (yellow segment) followed by spring. The lowest frequency of LLWS events occurs in winter in more than two-thirds of the airports (14 out of 20, green segment). In total, the frequency of LLWS events at most airports in Chinese mainland is the highest or at least the second highest in spring, which is mainly associated with the frequently passing cold fronts and strong winds in spring. Furthermore, this generally shows a similar monthly frequency distribution of LLWS reports from most airports in the same geographical regions, as indicated in the right axis in Figure 10, where they are likely to be affected by similar weather systems and patterns.

For example, at most airports in North China and Northeast China, namely, ZYHB, ZYTX, ZBHH, ZBYN and ZBTJ, the highest frequency of LLWSs occurs in spring with the most in April or May, followed by summer and then autumn and winter. Moreover, the frequency in spring is much higher than that in summer. Meanwhile, LLWSs at the other three primary airports (ZBAA, ZYTL and ZYCC) also show the highest frequency in spring, though the second highest is in winter at ZBAA and in autumn at ZYTL and ZYCC. On the whole, the characteristics of the monthly frequency of LLWS reports at airports in the northern, northeastern and northwestern part of China are quite similar, which is largely due to the strong winds caused by the activities of cold air, passing cold frontal systems or low-pressure troughs in spring and convective weather in summer in these areas. This also contributes to a similar monthly variation of LLWS reports at ZSQD and ZSPD commonly affected by the same weather systems.

Specifically, due to the unique wind-shear conditions, particularly the specific topography, the seasonal variation of LLWS reports show some differences at particular airports. Concerning the characteristics of LLWS at ZBAA, the cumulative monthly frequency of LLWS during 2016-2020 indicates that the most LLWS reports are in spring followed by winter, agreeing with the results of a previous study based on the PIREPs during 20072008 [19], while also differing somewhat from the result indicating the highest frequency is in winter followed by spring based on the PIREPs during 2010-2014 [20]. Since ZBAA is located in the northern margin of the North China Plain, surrounded on three sides (west, north and east) by mountains, the prevailing strong northwesterly winds in winter and spring interact with the terrain, making it vulnerable to the frequent LLWSs. As for ZYTL, the airport is located in the hilly area of Liaodong Peninsula, where strong northerly and northwesterly winds are often prevalent in autumn and spring. The monthly variation denotes that the high frequency of LLWS occurs mostly in March, secondly in May, and then in April, January, October and November, which also largely agrees with the previous 
investigation that noted the highest frequency in April, the second-highest in May, and the following in October and November based on the PIREPs from 2011 to 2018 (both for the largest number of LLWS reports in spring and second-largest in autumn) but with a slight difference [21]. At ZBHH, the statistics in this study agree well with the results from a former study with the highest frequency in spring followed by summer during the period of 1996 and 2005 [26]. As the ZBHH airport is located in a mountainous area and surrounded on three sides (northwest, north and east) by high mountains, the frequent strong northwesterly and westerly winds in spring and thunderstorms in summer make LLWS occurrences more frequent.

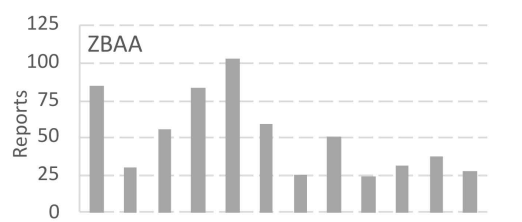

ZBH

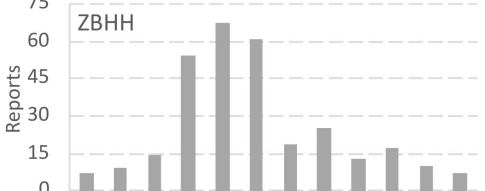

ZBYN

32

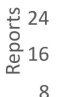

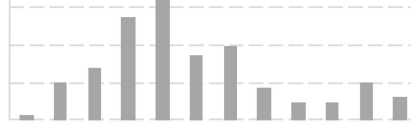

ZBTJ

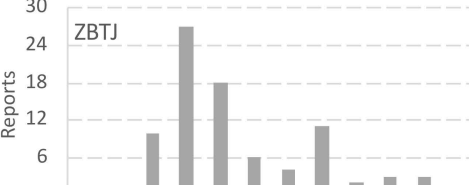

0

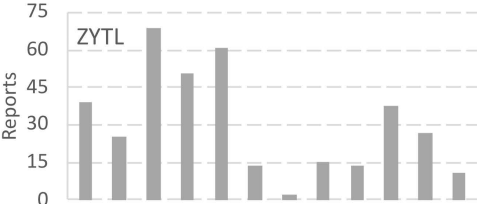

60
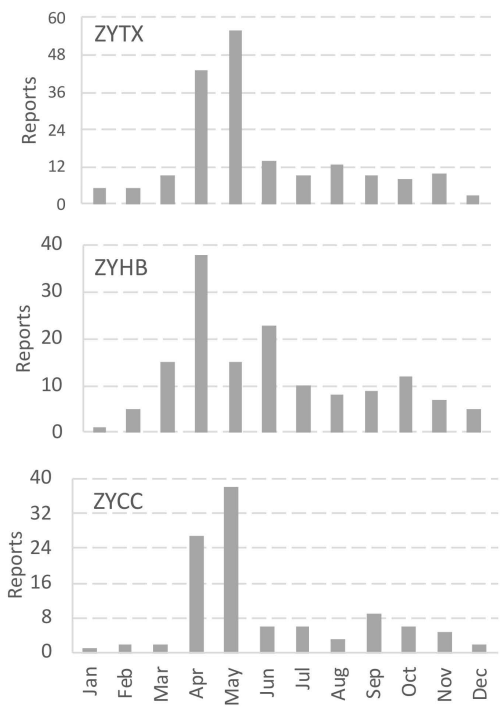

ZLLL

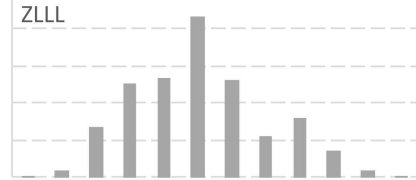

ZIXYY

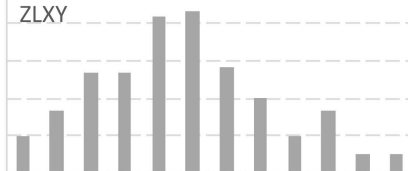

ZLIC

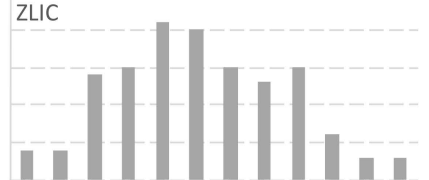

ZLXN

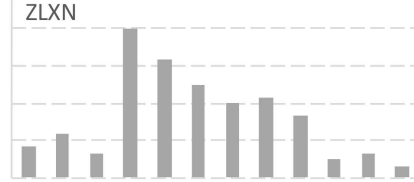

zWWW

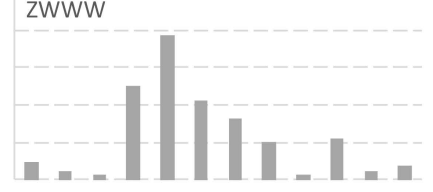

ZPPP
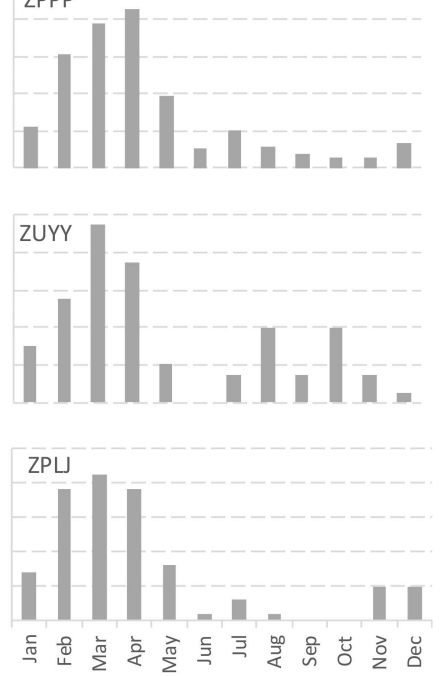

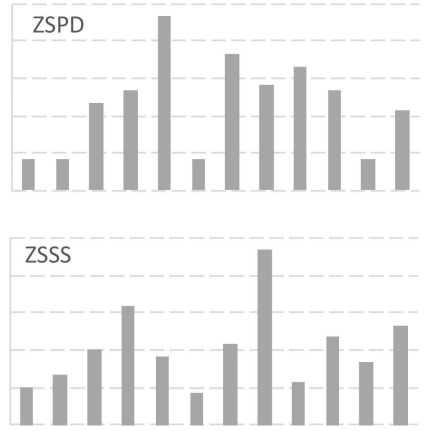

ZSQD
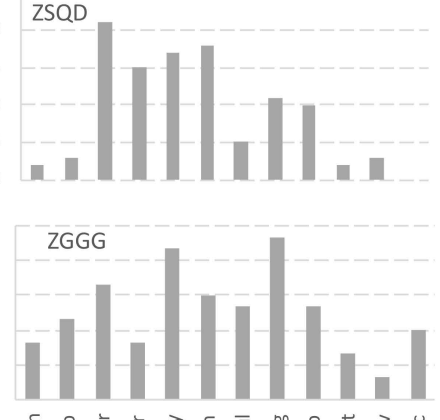

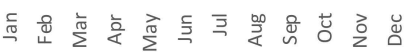

Figure 9. Cumulative monthly variation in LLWS reports at the 20 airports. 


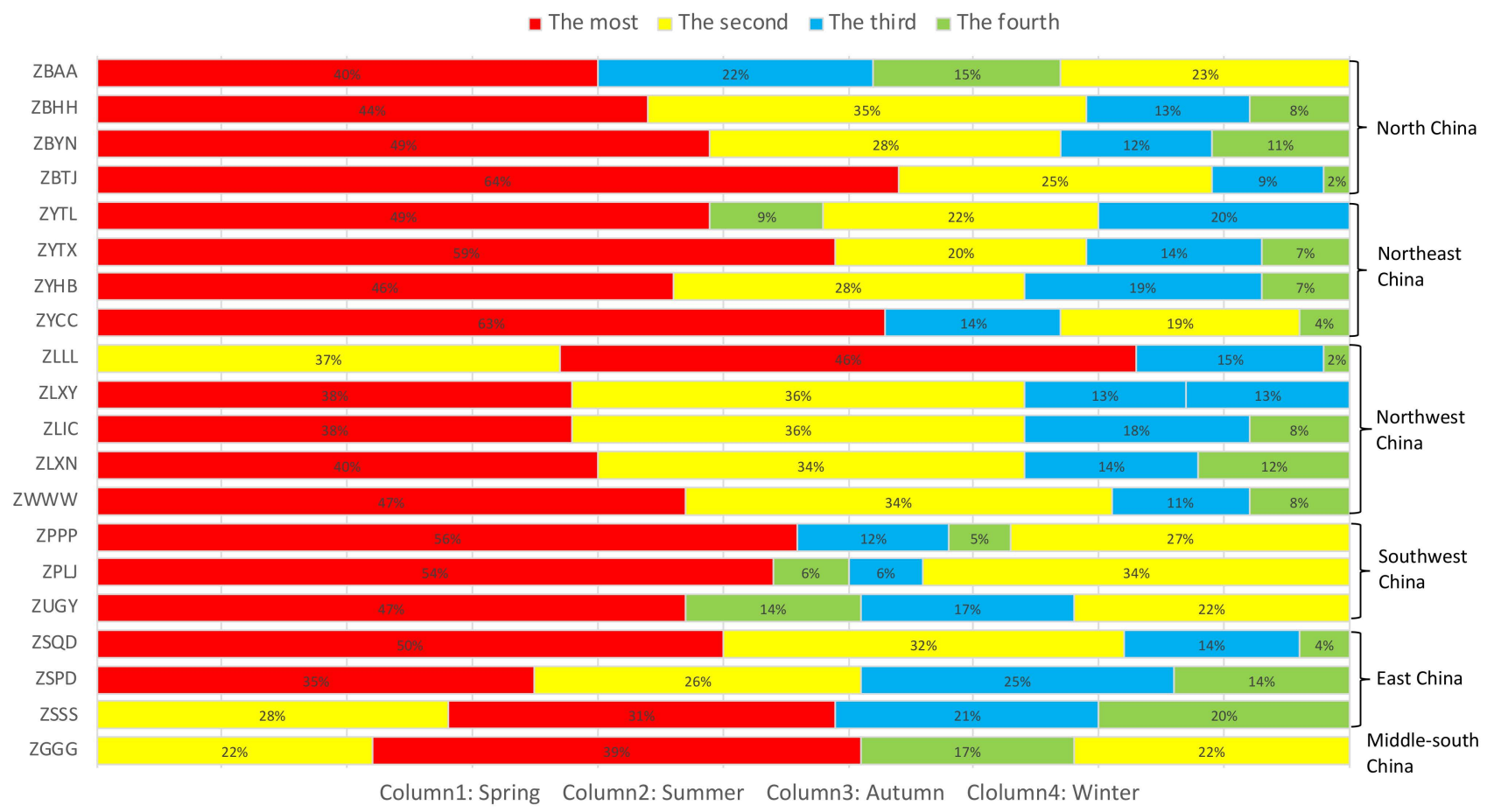

Figure 10. Cumulative seasonal variation of LLWS reports at the 20 airports.

In Northwest China, the highest frequency of LLWSs at most airports (ZLXY, ZLIC, ZLXN and ZWWW) is in spring followed by summer, but with no great difference between spring and summer at ZLXY, ZLIC and ZLXN. This mainly results from the frequent activities of cold and/or warm air and passing cold fronts in spring and thunderstorms or convective clouds in summer. For ZLLL specifically, with its particular topography and local conditions over the mountainous terrain, small-scale thunderstorms or convective clouds occur more often in summer or even in spring, resulting in the most frequent LLWS occurrence in summer, especially in June, which agrees with the results from the PIREPs during 2004-2007, but with the most in May followed by June [22].

At the three airports in Southwest China (ZPPP, ZUGY and ZPLJ), the highest frequency of LLWSs is in spring followed by winter, which is mainly related to the strong winds caused by low-level jet streams prevailing during January to April over the mountainous terrain and thermal lows prevailing in spring and the Yunnan-Guizhou quasistationary front $[27,28]$. For ZPPP, the result is consistent with that in the study based on reports from July in 2012 to July in 2016 [18].

Overall, the cumulative monthly frequency distribution of LLWS reports from most airports during 2016 to 2020 shows a similar monthly variation in LLWS as in previous studies, but with slightly differences.

\subsubsection{Diurnal Variation}

The diurnal variation in the frequency of LLWS reports is presented in Figure 11. Of interest is that the number of LLWS reports displays a pronounced diurnal cycle. The most frequent LLWS events occur from late morning to evening (from 10:00 to 19:59) in more than two-thirds $(67 \%)$ of the total LLWS reports, and in particular in the afternoon (from 12:00 to 16:59), in approximately $40 \%$ of the reports. The least frequent LLWSs occur after midnight to the early morning (from 01:00 to 06:59). The crest of the cycle appears in the afternoon with a peak of 450 reports (9.2\%) between 14:00 and 14:59, whereas the valley of the cycle is present after the midnight between 02:00 and 02:59 with the number of reports below 50. This implies that the diurnal variation of the frequency of LLWSs may be due 
to both the number of flights (with more operations during the daytime) and the weather conditions, which are much more unstable in the afternoon.

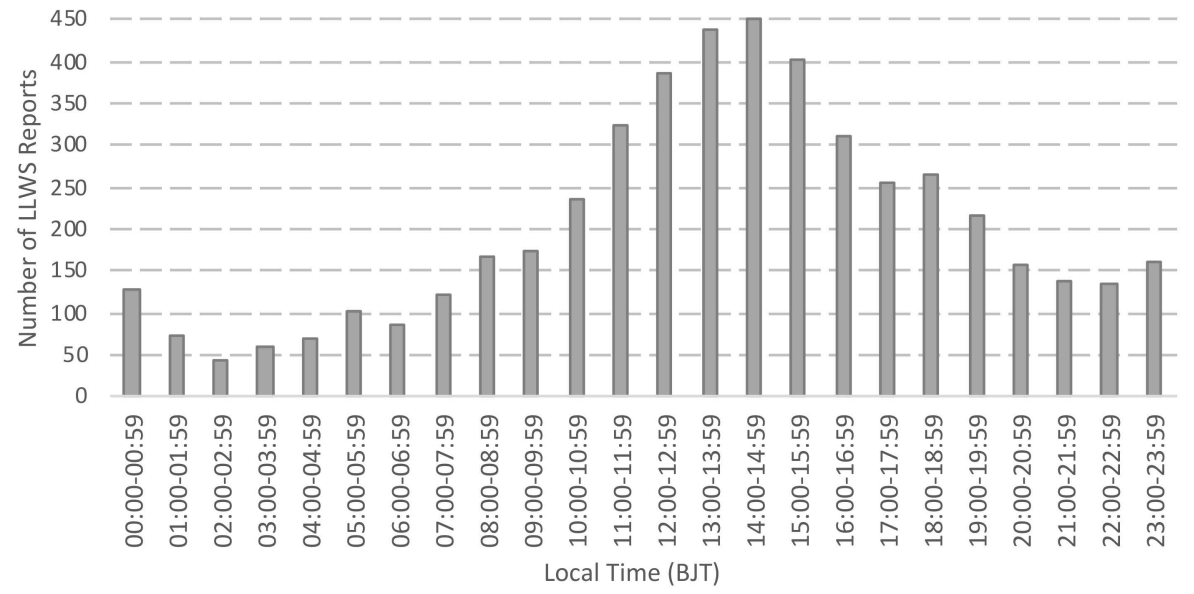

Figure 11. Overall diurnal variation of total LLWS reports.

Figure 12 presents the specific diurnal frequency distribution of LLWS reports at the 20 airports during the past five years. In total, there is no significant difference in the diurnal variation among these airports, most show a higher frequency during late morning to early evening and a lower frequency after midnight to early morning, as shown by the overall diurnal variation in Figure 11. In more details, the peak and the valley of the hourly frequency of LLWS reports are slightly different at different airports. For example, there is generally only one peak of the hourly LLWS frequency for the majority of airports at one hour during 12:00-16:59, but two and three peaks only for ZWWW and ZPLJ, respectively. At ZWWW, the LLWS reports increase after 22:00 and reach a peak at 00:00-00:59, with the same number of reports at 11:00-11:59 and 12:00-12:59 and no reports during 06:00-08:59. For ZPLJ, there are three peaks at the hours of 04:00-04:59, 11:00-11:59 and 14:00-14:59, while no reports are presented during 20:00-21:59. It is interesting that there is a relatively high frequency of LLWS reports at ZPLJ even after midnight, which shows that no significant fluctuations in variation of the frequency after 02:00 until 20:00. The frequency at ZSPD displays a similar distribution pattern, with no great fluctuation as, in ZPLJ, but for the whole diurnal cycle.

Furthermore, this demonstrates that for airports located in the same geographical area or where affected by similar weather systems, there is a similar pattern of the frequency distribution of LLWS reports. For example, for airports in North China, the hourly frequency increases from approximately early morning to early afternoon, reaching the crest at 14:00-14:59 at ZBAA, and at only one hour later (15:00-15:59) at the other primary airports (ZBHH, ZBYN and ZBTJ). The secondary peak at ZBHH, ZBYN and ZBTJ appears during 19:00-19:59.

It should also be noted that, except for the general increase in the frequency of LLWS reports after late morning for most airports, there is another marked increase before midnight, reaching a peak at 23:00-23:59 or 00:00-00:59 at some airports, such as ZYTL, ZYHB, ZBTJ and ZLIC at 23:00-23:59 and ZSPD, ZSQD, ZGGG, ZLXY and ZWWW at $00: 00-00: 59$. This is a change compared to the previous studies from earlier years in which there is generally no peak and even with no or very few reports during the midnight or several hours after midnight, which may be due to the increase in late-night flight operations in recent years. 

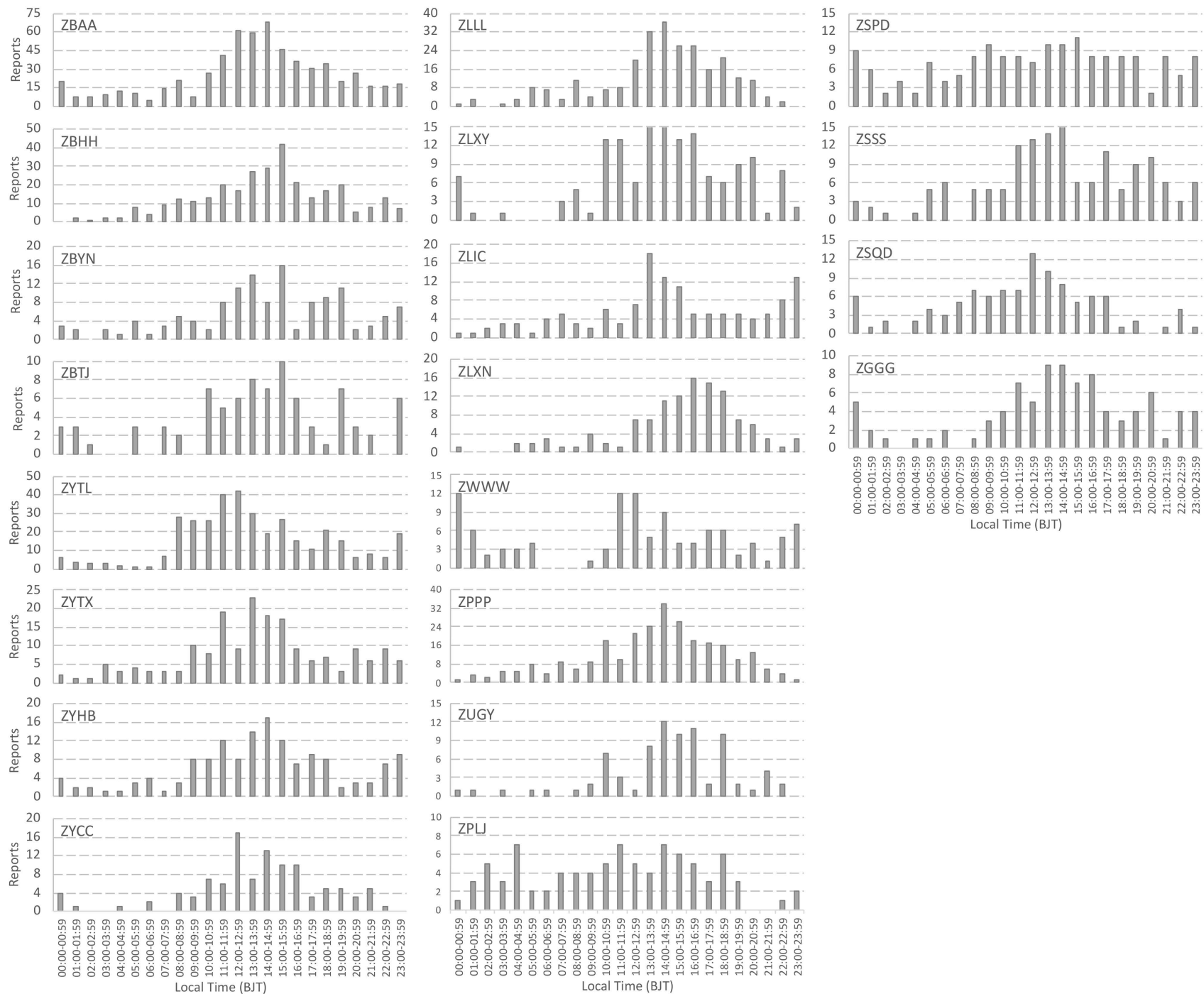

Figure 12. As in Figure 11, but for the 20 airports.

The general reason for the diurnal variation in LLWS reports at each airport is mainly the downward momentum propagation of upper strong winds in the afternoon, which results in strong low-level winds and the rapid variation of the wind direction due to active turbulent exchange in the afternoon. Combined with the high density of flight operations during this particular period and the local particular weather conditions for each airport, this results in the common characteristics of the diurnal frequency distribution of LLWS reports and the differing specific characteristics for different airports.

\section{Discussion and Conclusions}

This study investigated the spatial-temporal characteristics of LLWS over Chinese mainland using PIREPs, ATCREPs and the number of arriving and departing flights from 2016 to 2020. This paper focuses on an overview of the characteristics of the overall LLWS reports in Chinese mainland and the top 20 airports with the largest number of reports. It also explores the impacts of the flights operations on the number of LLWS reports.

According to the ATCREPs, approximately $30.7 \%$ reports related to LLWS reported aborted approaches, go-arounds, rejected take-offs or returns out of the total number reports associated with various factors. Combined with the two kinds of reports, nearly $76 \%$ of the reports of wind shear resulted in aborted approaches and/or go-arounds by the flights, demonstrating that the intensity of most of the wind shear reported was severe enough to seriously affect flight operation. This indicates that accurate detection, alerting 
and warning of LLWS is still important for the regularity, efficiency and even the safety of flight operations, even though the performance of the aircraft, operation procedures and flight technology have been improving.

The horizontal distribution shows that the largest number of LLWS reports are mostly distributed at or around airports with complex topography, mostly located in North China, Northeast China, Northwest China and Southwest China, with most affected by mountainous environments. The comparison of the number of LLWS reports and that of arriving/departing flights handled denotes that the top nine with the highest ratio appeared in airports ranked outside of the top 20 busiest airports in Chinese mainland by arriving/departing flights. This indicates that LLWS reports are not only related to the number of flights handled but also to the complexity of the topography and the prevailing weather conditions, especially for those systems causing strong low-level winds and sudden changes in wind direction. This agrees with the theoretical knowledge that the unique wind shear conditions over rough surfaces lead to more unstable atmospheric conditions in the lower planetary boundary layer and more LLWSs.

The vertical distribution of wind shear reports shows that wind shear is most likely to be reported at heights within 600m AGL (94\%) and especially within 300m (77\%). Compared with the cumulative frequency distribution in different airports, there are slight difference in the heights where most wind shear is reported. For instance, more than one quarter of wind shear reports occur above $600 \mathrm{~m}$ AGL at ZLXN. The characteristics of vertical distribution may be also related to the specific surrounding topography, especially along the approach path, and need further investigation.

The comparison of the inter-annual variation of the number of overall LLWS reports and arriving/departing flights displays a steady increase from 2016 to 2019 and a marked decrease from 2019 to 2020, consistent with the trend in the inter-annual variation of the number of flights, in which the decrease in flights from 2019 to 2020 is due to the worldwide COVID-19 pandemic. However, the impact of the number of flights on the number of LLWS reports is not evident for individual airports from 2016 to 2019, except for 2019 to 2020, which indicates that the impact is small unless the number of flights changes significantly.

Concerning the characteristics of monthly variation, there is no evident relationship between the monthly frequency distribution of LLWS reports and flights, which implies that the monthly variation in LLWS reports is largely related to the variation in weather conditions. The seasonal variation of the overall LLWS reports is evident, with the highest frequency in spring followed by summer. Moreover, the variation in the top 20 airports also exhibits obvious seasonal variation, with the highest frequency of LLWS in spring in the majority of airports (17 out of 20), with only three exceptions at ZLLL, ZSSS and ZGGG, where the most frequent LLWS occurs in summer followed by spring. By inference, this is mainly due to the combination of strong winds and the increase in surface temperature in spring resulting in much more active turbulent exchange than in winter, contributing to more LLWS events in spring, whereas in summer LLWS is mainly caused by convective weather or convective clouds. In addition, the frequency of LLWS at some airports is also high in winter, such as at ZBAA and three airports in Southwest China; this is also largely associated with the strong winds in winter caused by local prevailing weather conditions, especially cold air activities.

The diurnal variation in the LLWS reports is largely associated with the variation in flights handled during different periods of the day and the diurnal variation in local weather conditions, especially that the highest frequency of LLWS reports occur in the afternoon. The results of the highly frequent LLWS reports from the afternoon to early evening suggest that this is mainly caused by common, strong low-level winds occurring in the afternoon due to a downward transfer of momentum by upper strong winds, especially in spring in addition to the more convective weather conditions developed due to the heating and the greatest atmospheric instability in the afternoon. Moreover, compared to previous studies, an increase in LLWS frequency at midnight or late at night may be related to the increase in flights during that period. 
In general, the results of the temporal distribution of LLWS reports for most airports agree with those from previous studies but differ in certain details, such as the highest frequency of LLWS occurring in different seasons, different months or different periods. This is likely because the number of LLWS reports in previous studies is relatively smaller, in earlier years being based only on the PIREPS, while reports have increased by adding a new transmitting mode in recent years; the climate may also have changed, which requires further consideration.

This study has thus focused on an overview of the characteristics of the LLWS over the whole of Chinese mainland and presents some preliminary results and a causal analysis for the top 20 airports affected by LLWS. It can help to recognize which airports are most severely impacted by LLWS, the vertical range with a higher density of LLWS and the most frequent month and period of LLWS, as in addition to the likely mechanisms. On the one hand, this study provides a reference for feasibility studies regarding which equipment to install, where to better detect wind shear and how to design the alerting algorithm according to the causes of LLWS. On the other hand, it is also useful for weather forecasters who may need to know the characteristics of LLWS and to improve their understanding and skills regarding the LLWS warning and forecasting. Future efforts will be focused on detailed analyses and investigations of the causal inferences for wind shear and its more particular characteristics at a specific airport, the application of advanced equipment for LLWS detection and alerting systems and how to warn and forecast LLWS more accurately in advance.

Author Contributions: Conceptualization, C.L., W.Z. and K.Z.; methodology, C.L., S.L. and W.Z.; validation, C.L. and K.Z.; formal analysis, C.L., X.C. and J.W.; investigation, K.Z., C.L. and X.C.; resources, C.L. and W.Z.; data curation, C.L. and S.L.; writing - original draft preparation, C.L. and X.C.; writing-review and editing, C.L., K.Z., X.C., S.L., J.W. and W.Z.; funding acquisition, C.L. and J.W. All authors have read and agreed to the published version of the manuscript.

Funding: This research was funded by the National Natural Science Foundation of China (No. U1433202) and the Independent Research Project of Key Laboratory of Civil Aviation Flight Technology and Flight Safety (FZ2020ZZ03).

Institutional Review Board Statement: Not applicable.

Informed Consent Statement: Informed consent was obtained from all subjects involved in the study.

Data Availability Statement: Data sharing not applicable to this article as no datasets were generated during the current study. The raw data required to reproduce these findings cannot be shared at this time as the data also forms part of an ongoing study.

Acknowledgments: We thank our colleagues for their kind support with the data collection.

Conflicts of Interest: The authors declare no conflict of interest.

\section{References}

1. Fichtl, G.H.; Camp, D.W. Sources of Low-Level Wind Shear around Airports. J. Aircr. 1977, 14, 5-14. [CrossRef]

2. International Civil Aviation Organization (ICAO). ICAO Safety Report, 2016 ed.; International Civil Aviation Organization (ICAO): Montreal, Canada, 2016; Available online: https:/ / www.icao.int/safety /Documents/ICAO_SR\%202016_final_13July.pdf (accessed on 2 December 2020).

3. International Civil Aviation Organization (ICAO). ICAO Safety Report, 2017 ed.; International Civil Aviation Organization (ICAO): Montreal, Canada; Available online: https://www.icao.int/safety/Documents/ICAO_SR_2017_18072017.pdf (accessed on 2 December 2020).

4. International Civil Aviation Organization (ICAO). ICAO Safety Report, 2018 ed.; International Civil Aviation Organization (ICAO): Montreal, Canada, 2018; Available online: https:/ / www.icao.int/safety/Documents/ICAO_SR_2018_30082018.pdf (accessed on 2 December 2020).

5. International Civil Aviation Organization (ICAO). ICAO Safety Report, 2019 ed.; International Civil Aviation Organization (ICAO): Montreal, Canada, 2019; Available online: https:/ / www.icao.int/safety /Documents/ICAO_SR_2019_final_web.pdf (accessed on 2 December 2020). 
6. International Civil Aviation Organization (ICAO). ICAO Safety Report, 2020 ed.; International Civil Aviation Organization (ICAO): Montreal, Canada, 2020; Available online: https://www.icao.int/safety/Documents/ICAO_SR_2020_final_web.pdf (accessed on 2 December 2020).

7. ICAO. Manual on Low-Level Wind Shear and Turbulence, 1st ed.; International Civil Aviation Organization: Montréal, QC, Canada, 2005; p. 222.

8. LOW-LEVEL WIND SHEAR ALERT SYSTEM (LLWAS). Available online: https://ral.ucar.edu/solutions/products/low-levelwind-shear-alert-system-1lwas (accessed on 10 December 2020).

9. Chan, P.W.; Shun, C.M.; Kuo, M.L. Latest Developments of Windshear Alerting Services at the Hong Kong International Airport. In Proceedings of the 14th Conference on Aviation, Range, and Aerospace Meteorology, Atlanta, GA, USA, 17-21 January 2010.

10. Shun, C.M.; Chan, P.W. Applications of an Infrared Doppler Lidar in Detection of Wind Shear. J. Atmos. Ocean. Technol. 2008, 25, 637-654. [CrossRef]

11. Zhang, P.; Chan, P.W.; Doviak, R.; Fang, M. Estimate of Eddy Dissipation Rate Using Spectrum Width Observed by the Hong Kong TDWR Radar. In Proceedings of the 34th Conference on Radar Meteorology, Williamsburg, VA, USA, 5-9 October 2009.

12. Chan, P.W.; Lee, Y.F. Application of Short-Range Lidar in Wind Shear Alerting. J. Atmos. Ocean. Technol. 2012, 29, 207-220. [CrossRef]

13. Chan, P.W.; Lee, Y.F. Application of a Ground-Based, Multi-Channel Microwave Radiometer to the Alerting of Low-Level Windshear at an Airport. Meteor. Z. 2011, 20, 423-429. [CrossRef]

14. Zhang, H.W.; Wu, S.H.; Wang, Q.C.; Liu, B.Y.; Yin, B.; Zhai, X.C. Airport Low-Level Wind Shear Lidar Observation at Beijing Capital International Airport. Infrared Phys. Technol. 2019, 96, 113-122. [CrossRef]

15. Zhang, H.; Liu, X.; Wang, Q.; Zhang, J.; He, Z.; Zhang, X.; Li, R.; Zhang, K.; Tang, J.; Wu, S. Low-Level Wind Shear Identification along the Glide Path at BCIA by the Pulsed Coherent Doppler Lidar. Atmosphere 2021, 12, 50. [CrossRef]

16. Li, L.Q.; Shao, A.M.; Zhang, K.J.; Ding, N.; Chan, P.W. Low-Level Wind Shear Characteristics and Lidar-Based Alerting at Lanzhou Zhongchuan International Airport, China. J. Meteor. Res. 2020, 34, 633-645. [CrossRef]

17. Zhao, D.; Zhou, L.; Yang, X. Kunming Airport Low Altitude Wind Shear Pattern and Wind Lidar application. Air Traffic 2017, 6, 59-63. (In Chinese)

18. Ma, M.J.; Lin, C.; Zhao, S.R.; Zhang, B.K.; Shen, H.X.; Wang, S.G. Characteristics and a Numerical Study of Low-Level Wind Shear over Beijing Capital International Airport. J. Lanzhou Univ. Nat. Sci. 2013, 49, 354-360. (In Chinese)

19. Shi, D.; Liang, S.; Wang, B. Time and Space Distribution characteristics of low Altitude Wind Shear and analysis of its reasons. Air Traffic 2014, 8, 41-43. (In Chinese)

20. Weng, X.; YU, J.; Xu, J. Cause Analysis of Typical Low-level Wind Shear in Dalian Airport. Meteorol. Environ. Sci. 2020, 43, 81-89. (In Chinese)

21. Dang, B.; Sun, W.Z.; Wang, J.Y.; Wei, L.B.; Shang, K.Z.; Li, J.X.; Wang, S.G. Analysis of Low-Altitude Wind Shear Cases at Lanzhou Zhongchuan Airport during 2004-2007. J. Lanzhou Univ. Nat. Sci. 2013, 49, 63-69. (In Chinese)

22. Xu, T. Characteristics of Low-level Wind Shear in Qinghai Xining Airport. IOP Conf. Ser. Mater. Sci. Eng. 2019, 688, 022030. [CrossRef]

23. Shen, H.B.; Zhao, R.H.; Zhang, X.; Li, Y.C. Analysis of Low-Level Wind Shear Events in Southwest China. Plat. Mount. Meteor Res. 2013, 33, 37-42. (In Chinese)

24. Hon, K.K. Predicting Low-Level Wind Shear Using 200-m-Resolution NWP at the Hong Kong International Airport. J. Appl. Meteorol. Clim. 2020, 59, 193-206. [CrossRef]

25. Li, L.Q.; Xie, N.J.; Fu, L.Y.; Zhang, K.J.; Shao, A.m.; Yang, Y. Impact of Lidar Data Assimilation on Low-Level Wind Shear Simulation at Lanzhou Zhongchuan International Airport, China: A Case Study. Atmosphere 2020, 11, 1342. [CrossRef]

26. Na, T. Analysis of Low-level Wind shear in Baita Airport. In Proceedings of the 2006 Annual Meeting of Chinese Meteorological Society, Sichuan, China, 25-27 October 2006. (In Chinese).

27. Yang, C.; Fu, Z.; Zhao, X. The characteristic analysis of Plateau Gale in Complex Mountainous Terrain. In Proceedings of the 2013 Annual Meeting of Chinese Meteorological Society, Nanjing, China, 23 October 2013). (In Chinese).

28. Wang, L.; Zhang, W.; Zhou, J. Statistic Analysis on the South-Westerly LLJ in China. J. Nanjing Inst. Meteor. 2003, 26, 797-805. (In Chinese) 